\section{ASTRONOMY}

\section{Star partners form strongest magnet}

Having a stellar partner might allow a dying star to become a magnetar - the strongest known magnet in the Universe - instead of a black hole.

Large stars usually form black holes when they die, so astronomers have wondered why some become magnetars, an unusual kind of neutron star. Simon Clarke of the Open University in Milton Keynes, UK, and his colleagues used the European Southern Observatory's Very Large Telescope to study the Westerlund 1 star cluster, which includes a magnetar.

They found a star that they say was probably the companion to the one that formed the magnetar. The two orbited each other closely, and as the larger one began to die, it transferred its outer layers to the smaller star. This made the small star rotate more rapidly, eventually creating an ultrastrong magnetic field.

Astron. Astrophys. 565, A90 (2014)

\section{PALAEONTOLOGY}

\section{Oldest sperm} found in fossil

Tiny fossil crustaceans found in Australia contain remarkably preserved giant sperm that are between 16 million and 23 million years old - the oldest reproductive cells ever discovered.

Renate Matzke-Karasz at Ludwig Maximilian University in Munich, Germany, and her colleagues examined ancient freshwater sediments in Queensland and used synchrotron X-rays to image the internal structure of fossil ostracods, crustaceans around 1 millimetre in length. The authors found well-preserved

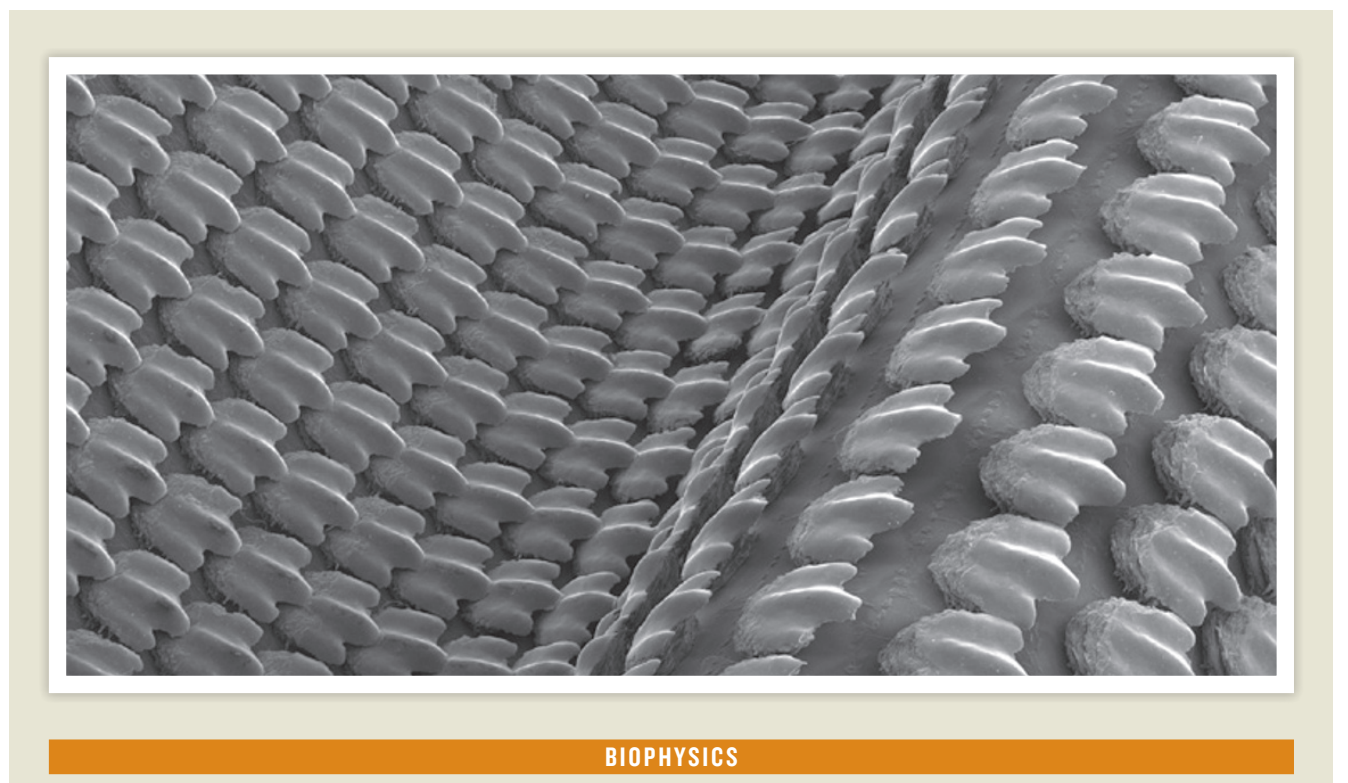

\title{
Fast swimming with fake shark skin
}

A material that mimics shark skin enables a swimming robot to move quickly through the water by improving hydrodynamics.

Li Wen, James Weaver and George Lauder at Harvard University in Cambridge, Massachusetts, used three-dimensional printing to embed thousands of rigid toothlike scales on a flexible membrane (pictured), based on the skin structure of the shortfin mako shark (Isurus oxyrinchus). The authors compared the synthetic shark skin to a smooth control model in a robot swim test and found that the experimental skin moved $6.6 \%$ faster.

The skin eases swimming both by reducing drag and by generating vortices that boost thrust, the authors suggest.

J. Exp. Biol. 217, 1656-1666 (2014) detail of soft tissue, including internal organs and sperm clusters around $1.2 \mathrm{~mm}$ long. The team even identified nuclei in some sperm.

Many modern ostracods have huge sperm relative to their body size, and these fossils show that the trait evolved long ago, although it is not clear why.

Proc. R. Soc. B http://doi.org/ssh (2014)

ORGANIC CHEMISTRY

\section{Simple recipe for small molecules}

A synthesis method that uses just one chemical reaction and 12 building blocks could allow chemists to automate construction of the backbones of thousands of small molecules.

This kind of modular simplicity is standard in the laboratory synthesis of proteins, nucleotides and, increasingly, carbohydrates. Martin Burke and his colleagues at the University of Illinois at Urbana-Champaign analysed more than 2,800 natural products, including pharmaceuticals, that contain polyene motifs - chains of carbon atoms connected by alternating single and double bonds. The researchers report that more than $75 \%$ of polyene structures can be made by sequentially linking building blocks from a small library of organic acid molecules that contain boron. These 'MIDA-boronates' were invented by Burke's group and are commercially available.

This approach avoids the need to invent a customized method for every polyenecontaining compound, the authors say.

Nature Chem. http://doi.org/ssv (2014)

\section{Spider genomes hold venom secrets}

Genome sequences from two spider species reveal the composition of their silk, and how spider venom exacts its toxic toll.

Mikkel Schierup at Aarhus 
tumours or inflammation during the nearly year-long study, and formed new bone.

The findings show the promise of iPS cells for repairing tissue in humans, the researchers say.

Cell Rep. http://doi.org/stw (2014)

University in Denmark and his team sequenced the genomes of o an African social velvet spider (Stegodyphus mimosarum) and a Brazilian white-knee tarantula (Acanthoscurria geniculata; pictured), and identified proteins that comprise the arachnids' venom

空 and silk. The venom of both species contains numerous protein-cleaving enzymes that probably activate precursors of toxic venom proteins. More than $70 \%$ of velvet-spider venom is made up of enzymes that break down fats.

The team also found that the velvet spider makes a more diverse array of silk proteins than the tarantula. That is probably because it uses its silk in a greater variety of ways, such as creating complex webs to capture prey, says the team. Nature Commun. 5, 3765 (2014)

\section{REGENERATIVE BIOLOGY}

\section{Stem cells make bone in monkeys}

Allowing a type of stem cell to mature before transplanting it into monkeys seems to prevent the cells from forming tumours or triggering inflammation two safety concerns that have plagued the field. Instead, the cells generated new tissue.

Induced pluripotent stem (iPS) cells can form a variety of tissues and can be made using a patient's own cells. Cynthia Dunbar at the National Institutes of Health in Bethesda, Maryland, and her team made iPS cells from the skin and bone marrow cells of two monkeys, and transplanted the cells back into the donor monkeys. These immature cells generated tumours and stimulated an inflammatory response. However, iPS cells that had developed into bone precursor cells before being transplanted did not cause

\section{GLACIOLOGY}

\section{Antarctic area is doomed to melt}

Several of Antarctica's glaciers

have already begun an unstoppable meltdown, two studies suggest.

Eric Rignot at the University of California, Irvine, and his colleagues used satellite radar to measure the retreat of five glaciers in West Antarctica and found that there is nothing holding the ice sheets back from catastrophic collapse, leaving them more vulnerable than previously thought. These glaciers hold enough water to raise the global sea level by 1.2 metres.

A team led by Ian Joughin at the University of Washington in Seattle modelled the behaviour of one of these glaciers, the Thwaites Glacier, and found that it is permanently destabilized. The melting of Thwaites will probably raise sea levels by 2.5 centimetres over the next century and by more than a millimetre per year within two to nine centuries, the team says. Geophys. Res. Lett. http://doi.org/ srf (2014); Science 344, 735-738 (2014)

\section{Plastics recycled with acid}

The plastics often found in electronics typically cannot be recycled, but researchers have come up with a way of producing polymers that can be broken down into reusable monomers using acid.

Jeannette Garcia and James Hedrick at the IBM Almaden Research Center in San Jose, California, and their colleagues created a strong and stable material

SOCIAL SELECTION

\section{Family history wins gene debate}

Discussion on social media about a recent genetics talk propelled a five-year-old paper into the limelight. Yale University bioinformatician Mark Gerstein, while at the Biology of Genomes meeting in Cold Spring Harbor in early May, live-tweeted a provocative quote from Stanford University geneticist Mike Snyder's talk: "Your genome is [a] better record of your family history than your family." A lively Twitter debate ensued. Geneticist Leonid Kruglyak of the University of California, Los Angeles, following the conference hashtag from afar, tweeted a dissenting view: "Family history wins: Predicting human height by Victorian and genomic methods." He linked to a 2009 paper showing that a simple average of the parents' heights could predict a person's height better than a genetic profile of 54 locations along the genome. Aulchenko, Y. S. et al. Eur. J. Hum. Genet. 17, 1070-1075 (2009)

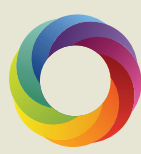

Based on data from altmetric.com. Altmetric is supported by Macmillan Science and Education, which owns Nature Publishing Group.
DNATURE.COM

For more on popular papers: go.nature.com/tta69i called a thermoset polymer, used in automotive, aerospace and electronic parts. They linked together aminebased monomers with paraformaldehyde to form the thermoset. By exposing the material to acid solutions of less than $\mathrm{pH} 2$, the researchers ended up with the monomer building blocks that they could then reuse.

Science 344, 732-735 (2014)

\section{ANTHROPOLOGY}

\section{Siberian origin for Native Americans}

The discovery of a roughly 12,000-year-old human skeleton lends weight to the theory that Native Americans descended from Siberian migrants, rather than from people in a later migration.

Ancient American skulls look different from those of modern Native Americans, leading some to think that Native American ancestors arrived after humans first crossed the land bridge between Siberia and North America some 26,000 to 18,000 years ago.
James Chatters of Applied Paleoscience in Bothell, Washington, and his co-workers studied a nearintact skeleton of a teenage girl found in an underwater cave in Mexico (pictured). Analysis of the bones revealed features similar to those of other ancient Americans. However, DNA extracted from a tooth carried a genetic signature that occurs only in Native Americans.

The results suggest that evolution on American soil led to the differences between ancient and Native Americans. Science 344, 750-754 (2014)

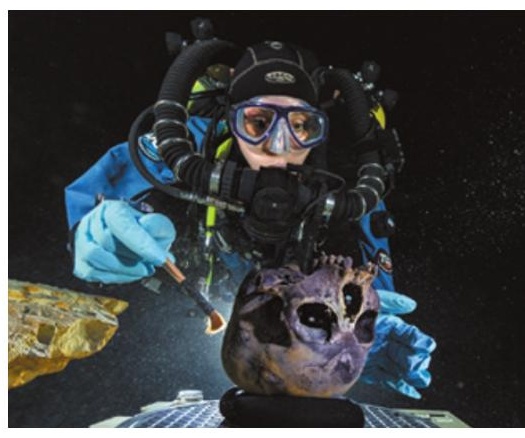

D NATURE.COM

For the latest research published by Naturevisit:

www.nature.com/latestresearch 